\title{
Copper Determination in Gunshot Residue by Cyclic Voltammetric and Inductive Coupled Plasma-Optical Emission Spectroscopy
}

\author{
Nurul'Afiqah Hashimah Mohd Hashim ${ }^{1}$, Zainiharyati Mohd Zain ${ }^{1}$ and Mohd Zuli Jaafar ${ }^{2}$ \\ ${ }^{1}$ Faculty of Applied Sciences, Universiti Teknologi MARA, 40450 Shah Alam, Malaysia \\ ${ }^{2}$ Universiti Teknologi MARA, 77300 Jasin, Malaysia
}

\begin{abstract}
Analysis of gunshot residue (GSR) is a crucial evidences for a forensic analyst in the fastest way. GSR analysis insists a suitable method provides a relatively simple, rapid and precise information on the spot at the crime scene. Therefore, the analysis of $\mathrm{Cu}(\mathrm{II})$ in GSR using cyclic voltammetry (CV) on screen printed carbon electrode (SPCE) is a better choice compared to previous alternative methods such as Inductive Coupled Plasma-Optical Emission Spectroscopy (ICP-OES) those required a long time for analysis. SPCE is specially designed to handle with microvolumes of sample such as GSR sample. It gives advantages for identification of copper in GSR on-site preliminary test to prevent the sample loss on the process to be analyzed in the laboratory. SPCE was swabbed directly on the shooter's arm immediately after firing and acetate buffer was dropped on SPCE before CV analysis. For ICP-OES analysis, cotton that had been soaked in $0.5 \mathrm{M}$ nitric acid was swabbed on the shooter's arm immediately after firing and kept in a tightly closed sampling tube. Gold coated SPCE that had been through nanoparticles modification exhibits excellent performance on voltammograms. The calibration was linear from 1 to $50 \mathrm{ppm}$ of copper, the limit of detection for copper was $0.3 \mathrm{ppm}$ and a relative standard deviation was $6.1 \%$. The method was successfully applied to the determination of copper in GSR. The $\mathrm{Cu}$ determination on SPCE was compared and validated by ICP-OES method with $94 \%$ accuracy.
\end{abstract}

\section{Introduction}

Gunshot residue is classified into forensic microtraces category [1] which is valuable evidence in the forensic analysis [2]. This is due to the condensation of metallic particles from the primer of a firearm discharged that is characterized by their uniqueness of chemical content and morphology of GSR [3]. It provides very useful information for forensic analysts to obtain the information about the type of gun and ammunition used in a crime when proper methods are used [2,4]. A suitable method used in GSR analysis offers more reliable results in reducing the erroneous convictions [4].

Many GSR analyses were reported using different techniques separately for identification organic or inorganic compounds. The organic compounds that are usually obtained in GSR sample are methyl centralite, ethyl centralite and diphenylamine [5]. Inorganic components that had been detected as reported in the previous study are lead, barium [6-9] and antimony [6,7].

Analysis of organic compounds in GSR was implemented by a combination of solid-phase microextraction (SPME) and gas chromatography mass spectrometry (GC-MS) technique [10], desorption electrospray ionization mass spectrometry (DESI-MS) [5] and fourier transform infrared (FTIR) spectroscopy [11].
Analyses of inorganic compounds commonly used scanning electron microscope energy dispersive $\mathrm{x}$-ray spectrometer (SEM-EDS) [12-15], sector field inductively coupled plasma mass spectrometer (SF-ICPMS) [6], inductively coupled plasma atomic emission spectrometer analysis (ICP-AES), ion beam analysis particle induced $\mathrm{x}$-ray emission (IBA-PIXE) [7], Raman spectroscopy [2], capillary electrophoresis [16], ion chromatography [17], differential pulse anodic stripping voltammetry (DPASV) [8], cyclic voltammetry [4] and abrasive stripping voltammetry (AbrSV) [18].

A fast and precise technique in GSR analysis is needed for identifying and discriminating firearm ammunition and GSR rapidly. Salles et al. in 2012 was proposed a fast electrochemical technique that can be miniaturized and applied in GSR analysis. Electrochemical analysis provides simple responses to different samples and is generally cheaper compared with other conventional spectroscopic methods such as atomic absorption spectrometry and mass spectrometry. Cyclic voltammogram $(\mathrm{CV})$ is a selected method than the other electrochemical technique for GSR analysis. GSR was collected from the hands of the shooters before analyzing using CV and a gold microelectrode as the electrode [4].

Recently, analysis of GSR had been performed by voltammetry of microcrystals or abrasive stripping voltammetry (AbrSV) which one of an electrochemical 
technique. The metal deposited produces an analytically diagnostic signal in stripping voltammetry. It is a very suitable method for GSR analysis those contain organic components [19-20]. AbrSV technique had been implemented in GSR analysis based on an initial mechanical transfer of trace amounts of the GSR from the hand of the suspect directly to the surface of the workingelectrode sensor strip without intermediate processing steps. The used of screen-printed carbon (SPE) as a working electrode in this abrasive technique is an alternative way to overcome the limitations related with the effective collection of residues and simplifying the overall electroanalytical protocol [18].

\section{Experimental}

Chemical and Materials. Acetate buffer (0.7 M, pH 4.6) and standard solutions of copper (1000ppm) were purchased from Fluka (St. Louis, MO). A range of 1 to 50 ppm of copper standard solution was made from the copper stock solution. Deionized water $(18 \mathrm{M} \mathrm{M} \Omega \mathrm{cm})$ from a NANOpure Diamond system (Thermo Scientific, Dubuque, IA) was used to prepare all solutions. Both SPCE and gold coated SPCE were purchased from Metrohm (The Netherlands) used for all measurements.

Instruments and Procedure. An Autolab PGSTAT 12 (Eco Chemie, The Netherlands) was used to perform electrochemical (cyclic voltammetry) measurements and an Inductively Coupled Plasma Optical Emission Spectrometry (ICP-OES) instrument (Perkin Elmer, Optima 2100DV, USA) was used for the quantification of copper.

GSR Sampling. GSR samplings were performed in enclosed areas at Science and Technology Research Institute for Defense (STRIDE) at Batu Arang, Selangor. Glock with $9 \mathrm{~mm}$ ammunition, Rifle Stryer AUG-A1 with $5.56 \mathrm{~mm}$ ammunition and Rifle Colt M16-A1 with 5.56 $\mathrm{mm}$ ammunition were used in this work. GSR triplicates sampling was carried out in two ways; gold coated SPCE was directly swabbing on the shooter's arm for voltammetric determination. Secondly, cotton swab that was soaked in $0.5 \mathrm{M}$ of nitric acid was swabbed on the shooter's arm and kept in a tightly closed sampling tube.

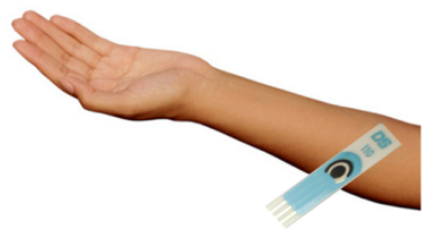

Figure 1. SPCE swabbed on the shooter's arm

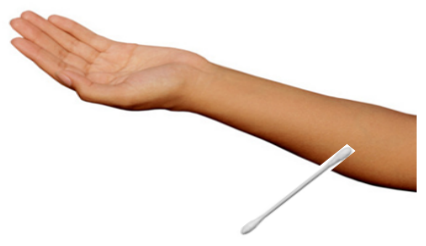

Figure 2. Soaked cotton swabbed on the shooter's arm

Cyclic Voltammetry (CV). Cyclic voltammetry was applied to characterize GSR electrochemical signatures. 3-electrode strip surface was immediately swabbed after firing on the shooter's arm. $20 \mu \mathrm{L}$ of acetate buffer was dropped on SPCE and immediately analyzed using cyclic voltammetry on-site preliminary test. Scan potential of 100 to $100 \mathrm{mV}$ and scan rate of $100 \mathrm{mVs}^{-1}$ was set up as operating parameters.

Inductive Coupled Plasma-Optical Emission Spectroscopy (ICP-OES). GSR samples were collected by swabbing cotton soaked in $0.5 \mathrm{M}$ of nitric acid on the shooter's arm. Then the swabbed cottons were soaked in $0.5 \mathrm{M}$ of nitric acid overnight. Operating parameters were set up as follows: $1500 \mathrm{~W}$ of a RF power, $15 \mathrm{Lmin}^{-1}$ of a plasma flow rate, $0.2 \mathrm{Lmin}^{-1}$ of an auxiliary gas flow rate and $0.8 \mathrm{Lmin}^{-1}$ of a nebulizer flow rate. Argon was used to purge the optics and to form the plasma.

\section{Result and Discussion}

Voltammetric Response of $\mathbf{C u}($ II). Prior to membrane deposition, electrochemical behavior of $\mathrm{Cu}(\mathrm{II})$ was studied using CV on SPCE. CV scans for 1 to $50 \mathrm{ppm}$ of $\mathrm{Cu}(\mathrm{II})$ solutions at a constant scan rate of $100 \mathrm{mVs}^{-1}$ are shown in Fig. 3. The electrochemical oxidation of $\mathrm{Cu}(0)$ to $\mathrm{Cu}$ (II) by $\mathrm{CV}$ can be observed at even very low $\mathrm{Cu}$ (II) concentrations. The cyclic voltammograms show the peak current linearly increases as the concentration $\mathrm{Cu}(\mathrm{II})$ increased. This is due to increasing the rate of diffusion of $\mathrm{Cu}$ (II) towards the electrode surface. The presence of a large amount of electroactive species at higher concentration cause a gradual increase of peak current with the increase of $\mathrm{Cu}(\mathrm{II})$ concentration. The system follows a diffusion controlled system [20]. A linear graph was obtained in the concentration range from 1 to $50 \mathrm{ppm}$ (slope $\left.=5754, \mathrm{R}^{2}=0.9923\right)$. 


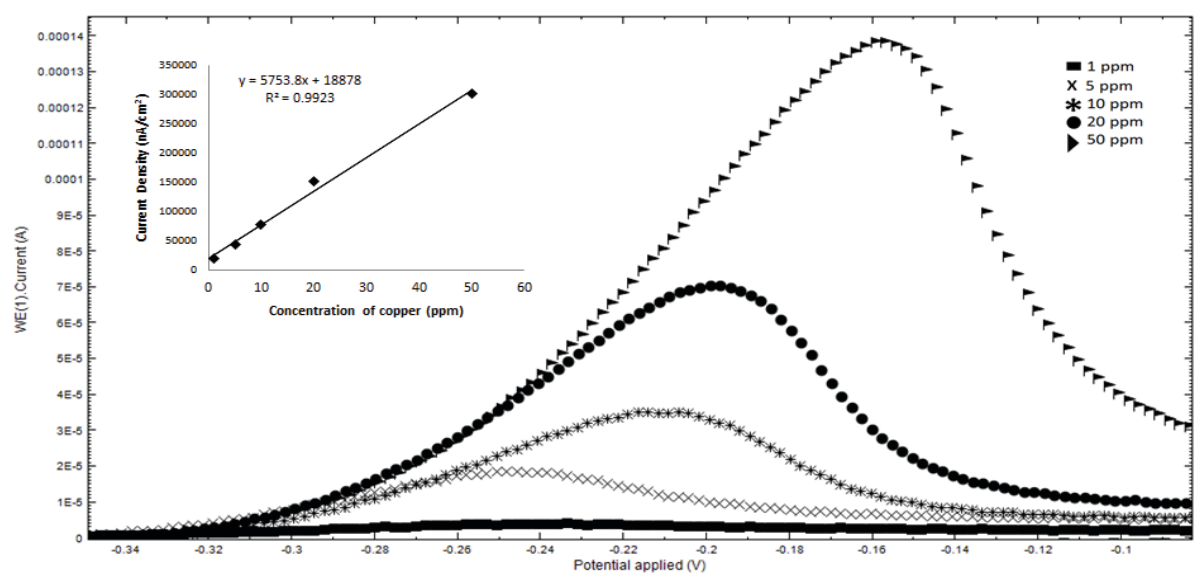

Figure 3. Cyclic voltammograms of 1,5,10,20 and $50 \mathrm{ppm}$ of $\mathrm{Cu}$ (II). Insets show the calibration curve of $\mathrm{Cu}$ (II) concentration

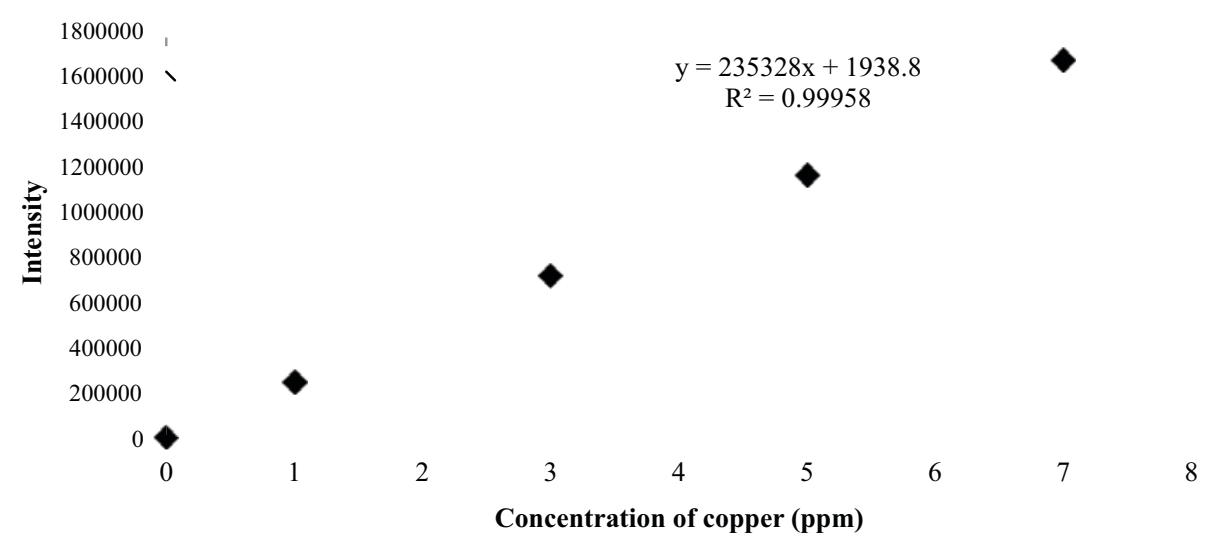

Figure 4. Calibration curve for ICP-OES for 1-10 ppm $\mathrm{Cu}(\mathrm{II})$

ICP-OES of Cu(II). At ICP-OES analysis, a reasonable linearity was obtained upon introducing an increasing concentration of $\mathrm{Cu}(\mathrm{II})$ as shown in Fig. 4. A calibration curve established for identification of $\mathrm{Cu}$ (II) in GSR. A linearity response was obtained in the concentration range 1 to $7 \mathrm{ppm}$ (slope $=235328$, $\left.\mathrm{R}^{2}=0.9996\right)$. The reproducibility of the gold coated SPCE was also evaluated and it was found to be good with relative standard deviation (RSD) of $6.1 \%(n=3)$.

Comparison of $\mathrm{CV}$ and ICP-OES. Both methods show the lower sensitivity for identification of $\mathrm{Cu}(\mathrm{II})$. However, in terms of practicality $\mathrm{CV}$ shows more convenient method. CV analysis on SPCE is a rapid and reliable tool in determination of $\mathrm{Cu}(\mathrm{II})$ in gunshot residue. These advantages of SPCE enable the quantification of $\mathrm{Cu}(\mathrm{II})$ in GSR on the spot at the crime scene.

Comparison of the performance of SPCE and gold coated SPCE. The performances of $\mathrm{Cu}$ (II) on both SPCE and gold coated SPCE were observed. It shows the gold coated SPCE exhibits excellent reproducibility rather than SPCE in aspects of current produced in cyclic voltammograms. Modification of electrodes using nanoparticles enhance electrochemical performance due to their large effective surface area, effective catalysis and fast mass transport [21-22] 


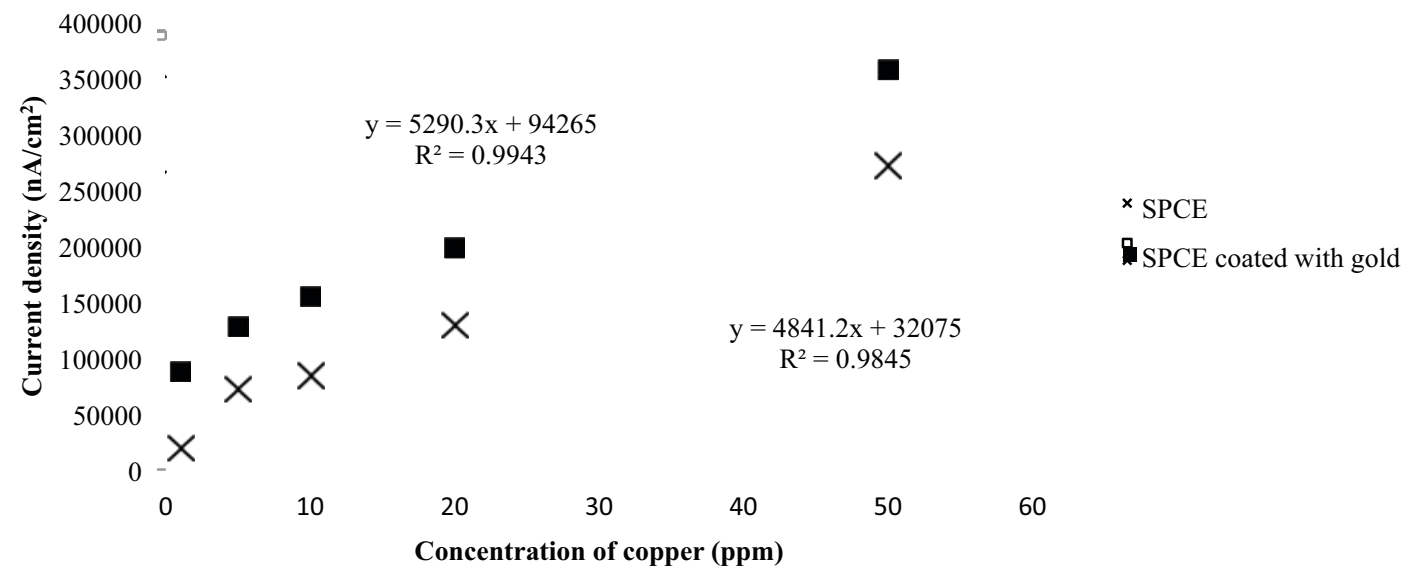

Figure 5. Comparison performances of SPCE and gold coated SPCE for the concentration of 1 to $50 \mathrm{ppm}$ of $\mathrm{Cu}$ (II)

GSR Analysis. The copper content in GSR was determined using both cyclic voltammetry and ICP-OES. The Student's t-test was applied to the results obtained by $\mathrm{CV}$ and those found using ICP-OES, and comparison is shown in Table 1. The paired Student's t-test indicated that there was no significant difference between the results obtained from both methods at the $94 \%$ confidence level. Therefore, it can be concluded that $\mathrm{CV}$ is reliable and can be successfully applied to the copper determination in GSR analysis. Based on the analysis of results, it can be seen that the amount of copper present in the GSR from the Rifle Stryer AUG-A1 higher compared to both Rifle Colt M16-A1 and Glock.

Table 1. Results obtained from CV and ICP-OES methods for analysis of GSR samples

\begin{tabular}{|c|c|c|c|c|}
\hline Gun & Ammunition & Voltammetric $\quad\left[\mathrm{ppm} \mathrm{Cu} \mathrm{Cu}^{2+}\right]$ & $\begin{array}{c}\text { ICP-OES } \\
\left.\mathrm{Cu}^{2+}\right]\end{array}$ & $t_{\text {calculated }}$ \\
\hline Rifle Colt M16-A1 & 5.56 & $0.707 \pm 0.01$ & $0.748 \pm 0.002$ & 0.04 \\
\hline Rifle Stryer AUG-A1 & 5.56 & $1.349 \pm 0.02$ & $1.432 \pm 0.005$ & 0.03 \\
\hline Glock & 9 & $0.680 \pm 0.01$ & $0.724 \pm 0.005$ & 0.01 \\
\hline
\end{tabular}

\section{Conclusion}

Cyclic voltammetry analysis on SPCE is the perfect combination for the quantification of copper in GSR for a forensic analyst in the fastest way at the crime scene. The performance of $\mathrm{Cu}(\mathrm{II})$ on gold coated SPCE shows excellent reproducibility due to their large effective surface area, effective catalysis and fast mass transport.

\section{Acknowledgement}

Financial and technical support from The Ministry of Education through the Fundamental Research Grant Scheme (FRGS) and Universiti Teknologi MARA are highly acknowledged.

\section{References}

1. K. Štůlová, T. Vaculovič and V. Kanický: Mendel Net. (2013) p. 940-944

2. M. López-López, J. J. Delgado and C. García-Ruiz: Forensic Sci. Int. Vol. 231, No. 1-5 (2013) p. 1-5

3. Z. Brozek-Mucha and J. Was-gubala: Current Microscopy Contributions to Advances in Science and Tech.(2012) p. 1480-1491
4. M. O. Salles, M. Bertotti and T. R. L. C. Paixão: Sensors Actuators B Chem. Vol. 166-167, p. 848852

5. M. Morelato, A. Beavis, A. Ogle, P. Doble, P. Kirkbride and C. Roux: Forensic Sci. Int. Vol. 217, No. 1-3 (2012) p. 101-6

6. J. E. S. Sarkis, O. N. Neto, S. Viebig and S. F. Durrant: Forensic Sci. Int. Vol. 172, No. 1 (2007) p. 63-6

7. E. Turillazzi, G. P. Di Peri, A. Nieddu, S. Bello, F. Monaci, M. Neri, C. Pomara, R. Rabozzi, I. Riezzo and V. Fineschi: Forensic Sci. Int. Vol. 231, No. 1-3 (2013) p. 142-9

8. C. A. Woolever, D. E. Starkey and H. D. Dewald: Forensic Sci. Int. Vol. 102, No. 1 (1999) p. 45-50

9. M. O. Salles, J. Naozuka and M. Bertotti: Microchem. J. Vol. 101 (2012) p. 49-53

10. C. Weyermann, V. Belaud, F. Riva and F. S. Romolo: Forensic Sci. Int. Vol. 186, No. 1-3 (2009) p. 29-35

11. J. Bueno, V. Sikirzhytski and I. K. Lednev: Analytical Chem. Vol. 84, No. 10 (2012) p. 4334-9

12. G. Zadora and Z. Brożek-Mucha: Mater. Chem. Phys. Vol. 81, BN. 2-3 (2003) p. 345-348

13. S. Steffen, M. Otto, L. Niewoehner, M. Barth, Z. Brożek-Mucha, J. Biegstraaten and R. Horváth: Spectrochim. Acta Part B At. Spectrosc. Vol. 62, No. 9 (2007) p. 1028-1036 
14. B. Cardinetti, C. Ciampini, C. D’Onofrio, G. Orlando, L. Gravina, F. Ferrari, D. Di Tullio and L. Torresi: Forensic Sci. Int. Vol. 143, No. 1 (2004) p. 27-46

15. A. Martiny, A. P. C. Campos, M. S. Sader and A. L. Pinto: Forensic Sci. Int. Vol. 177, No. 1 (2008) p. e917

16. C. Love, E. Gilchrist, N. Smith and L. Barron: Forensic Sci. Int. Vol. 231, No. 1-3 (2013) p. 150-6

17. Š. Komorsky-Lovrić and B. Nigović: J. Electroanal. Chem. Vol. 593, No. 1-2 (2006) p. 125-130

18. Sebojka Komorsky-Lovric and I. Novak: Electrochimica Acta. Vol. 98 (2013) p. 153-156

19. A. Chatterjee, R. Wiltshire, K. B. Holt, R. G. Compton, J. S. Foord and F. Marken: Diam. Relat. Mater. Vol. 11, No. 3-6 (2002) p. 646-650

20. F. Haque, M. S. Rahman, E. Ahmed, P. K. Bakshi and A. A. Shaikh: Vol. 61, No. 2 (2013) p. 161-166

21. H. Wan, Q. Sun, H. Li, F. Sun, N. Hu and P. Wang: Sensors Actuators B Chem. Vol. 209 (2015) p. 336342

22. V. Sosa, C. Barceló, N. Serrano, C. Ariño, J. M. Díaz-cruz and M. Esteban: Analytica Chimica Acta. Vol. 855 (2015) p. 34-40 